\title{
EFFECTS OF BIAS VOLTAGE ON ADHESION AND PROPERTIES OF CHROMIUM NITRIDE THIN FILMS
}

\author{
Trung Van Trinh ${ }^{1 *}$, Tuan Hong Pham ${ }^{2)}$, Hop Thanh Nguyen ${ }^{2)}$, Thanh Van Nguyen ${ }^{1,3)}$ \\ ${ }^{1)}$ Hanoi University of Science and Technology, Ha Noi, Viet Nam \\ ${ }^{2)}$ National Center for Technological Progress, Ha Noi, Viet Nam \\ ${ }^{3)}$ Research Institute of Technology for Machinery, Ha Noi, Viet Nam
}

Received: 21.05.2019

Accepted: 02.12.2019

${ }^{*}$ Corresponding author: e-mail: trung.trinhvan@hust.edu.vn, Tel.: +84 243868 0409, School of Materials Science and Engineering, Hanoi University of Science and Technology, No.1 Dai Co Viet, Hai Ba Trung, Hanoi, Vietnam

\begin{abstract}
Thin films were deposited on SUS440 stainless steel samples by arc plasma evaporation at bias voltage range from - 10 to $-100 \mathrm{~V}$. X-ray diffraction, optical microscopy, field emission scanning electron microscopy, energy dispersive spectroscopy, microhardness test, and electrochemical test were used to investigate the morphology and properties of the thin films. Particularly, the thin films were composed of chromium nitride $(\mathrm{CrN}$, phases of $\mathrm{CrN}+\mathrm{Cr})$ and $0.76 \mu \mathrm{m}$ thick. They were deposited with microdroplets on the samples. The surface hardness of these films reached the highest value of $1492 \mathrm{HV}$ at the bias of $-20 \mathrm{~V}$. As the bias voltage increased, the adhesion of the $\mathrm{CrN}$ thin films decreased. The excessively high bias voltage of $-100 \mathrm{~V}$ led to the delamination of the $\mathrm{CrN}$ thin films. The electrochemical test demonstrated that the corrosion resistance in the $3 \% \mathrm{NaCl}$ solution of $\mathrm{CrN}$ coating can be improved.
\end{abstract}

Keywords: CrN, adhesion, bias voltage, SUS440, hard coating, corrosion resistant

\section{Introduction}

Chromium nitride $(\mathrm{CrN})$ is a bright silver-grey-colored coating that has a high hardness [1] and a good resistance to oxidation and corrosion [2,3]. It is widely used as an alternative for coating material to TiN in applications involving cutting, forming, and die casting of aluminum and zinc. Many techniques have been used to deposit $\mathrm{CrN}$ coatings, such as magnetron sputtering $[4,5]$, pulsed laser deposition [6], arc plasma evaporation [6 - 8], and ion assisted deposition [9 -11]. Among these techniques, arc plasma evaporation is the most popular in the industry due to its high deposition rate. The properties of coatings by this method strongly depend on the technological parameters of deposition, such as bias voltage, nitrogen pressure, substrate temperature, and arc current. Bias voltage and gas pressure are the key parameters that control deposition [11]. Meanwhile, pressure affects the chemical composition, phase structure, preferred orientation, and deposition rate of coatings. Chang deposited $\mathrm{CrN}$ coatings by arc ion plating. He reported that the microhardness of the $\mathrm{CrN}$ coatings by arc ion plating method increased from $1550 \mathrm{HK}_{50 \mathrm{~g}}$ to 2100 $\mathrm{HK}_{50 \mathrm{~g}}(2638 \mathrm{HV}$ to as nitrogen pressure increased from $0.4 \mathrm{~Pa}$ to $1.2 \mathrm{~Pa}$ primarily due to the variation in composition and structure [12]. The bias voltage can influence the nucleation and growth kinetics during coating growth and subsequently modify the microstructure and properties of coatings. Wang and Oki investigated how substrate bias voltage influences the orientation, morphology, and microhardness of reactive ion-plated $\mathrm{CrN}$ films using an ion plating. They 
reported a decrease in the microhardness of the films deposited at high bias voltages caused by a change in the microstructure from a dense columnar structure to a columnar structure with voided grain boundaries [13]. The adhesion and properties of coatings also strongly depend on the deposition method. Hence, the effects of bias voltages in arc plasma evaporation on the adhesion and properties of $\mathrm{CrN}$ are still further investigated.

In this study, CrN thin films were deposited on the SUS440 substrate under various bias voltages using an arc plasma evaporation system to improve the surface hardness and corrosion resistance of the SUS440 steel that can be applied for molds made of this steel. The effects of the bias voltages on the properties of the $\mathrm{CrN}$ thin films, such as surface morphology, adhesion, and surface hardness, were studied. The corrosion resistance of the $\mathrm{CrN}$ coatings was also investigated.

\section{Experimental procedures}

A SUS440 stainless steel bar with a composition of Fe-0.95C-17.20Cr-1.00Mn-1.00Si in wt.\% was cut into small samples with $18 \mathrm{~mm}$ diameter and $6 \mathrm{~mm}$ thickness. Then, it was austenitized at $1030{ }^{\circ} \mathrm{C}$ for $60 \mathrm{~min}$, quenched by oil, and tempered at $160{ }^{\circ} \mathrm{C}$ for $3 \mathrm{~h}$. After tempering, the hardness of the samples was $677 \mathrm{HV}(\cong 59 \mathrm{HRC})$, which is the normal hardness value for molds.

Prior to deposition, the SUS440 samples were ground by 1000 grit abrasive papers, polished, ultrasonically cleaned with acetone and alcohol, and then dried.

The SUS440 samples were mounted on a sample holder in the middle of the chamber of the arc plasma evaporation system (Dreva-400, Germany) to form the $\mathrm{CrN}$ thin films. A Cr target with a purity of $99.99 \%$ was used as the source for evaporation. The average distance between the $\mathrm{Cr}$ target and the SUS440 sample was $200 \mathrm{~mm}$. The temperature inside the chamber was increased to $300{ }^{\circ} \mathrm{C}$ by two lateral heaters. The working chamber was vacuumed to a pressure of $2.0 \times 10^{-2}$ $\mathrm{Pa}$. Then, Ar gas was introduced into the chamber at a flow rate of $60 \mathrm{sccm}$. The surfaces of the SUS440 samples were sputter-cleaned in a hollow cathode mode with a current of $120 \mathrm{~A}$ and a substrate bias of $-200 \mathrm{~V}$ for $15 \mathrm{~min}$. The flow rate of the Ar gas was reduced to $10 \mathrm{sccm}$. Then, $\mathrm{N}_{2}$ gas was introduced at a flow rate of $600 \mathrm{sccm}$ as the reactive gas. The target current was maintained at 120 A to deposit CrN thin films on the SUS440 samples. Deposition duration was set to $15 \mathrm{~min}$. The bias voltages were varied as $-10,-20,-30,-50$, and $-100 \mathrm{~V}$.

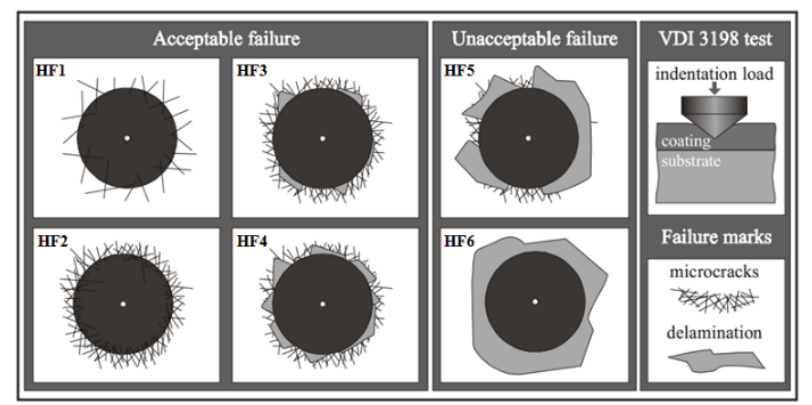

Fig. 1 Principle of the VDI 3198 indentation test [14]

The surface morphology of the $\mathrm{CrN}$ thin films was examined by field emission scanning electron microscopy (FESEM, JSM-7600F, JEOL) and optical microscopy (AxioVert 25A). The phase composition of these films were determined by X-ray diffraction with $\mathrm{Cu}-\mathrm{K} \alpha$ (X'Pert PRO, 
PANalytical). The $\mathrm{Cu}-\mathrm{K}_{\alpha}$ line at $0.15405 \mathrm{~nm}$ was used as the source for diffraction pattern analyses. Hardness testing was performed on a Vickers microindenter (Duramin 2, Struers) under a load of $10 \mathrm{~g}$ for $15 \mathrm{~s}$. The adhesion of the coatings to the substrates was studied in accordance with VDI 3198 standard procedures using Rockwell-C indenters with a load of $150 \mathrm{~kg}$; the adhesion was compared with adhesion strength quality maps via optical microscopy. The principle of this quality test is presented in Fig. 1. A conical diamond indenter penetrated the coated surface to induce massive plastic deformation to the coated film on the substrate and extreme shear stresses at the interface, thereby fracturing the coating. Good adhesion coatings will withstand these shear stresses and prevent extended delamination circumferentially. The four different textures from HF1 to HF4 illustrate the indentation shapes that guarantee strong adhesion of the coating on the substrate (HF is the German short form of adhesion strength.). However, the delamination (HF5 and HF6) at the vicinity of the indentation depicts poor interfacial adhesion [14]. The electrochemical measurements were performed in a standard three-electrode cell with 1 $\mathrm{cm}^{2}$ platinum counter electrode and a saturated calomel electrode as the reference electrode. The electrolyte was a $3.5 \% \mathrm{NaCl}$ solution. After each potentiodynamic polarization test, the corrosion potential $\left(\mathrm{E}_{\text {corr }}\right)$ and the corrosion current density $\left(\mathrm{I}_{\text {corr }}\right)$ can be determined by a Tafel plot.

\section{Results and discussion}

Fig. 2 shows the analytical results of a deposited CrN thin film with at $-20 \mathrm{~V}$ bias on one SUS440 sample. A featureless surface morphology of this film examined by SEM is shown in Fig. 2a with microdroplets. These microdroplets seem to be $\mathrm{Cr}$ particles that cannot be ionized totally from the target. The Cr phase is attributed to incorporated microdroplets, which have previously been reported to have a core consisting of pure metal phase $[15,16]$. Fig. $2 b$ presents a cross-sectional SEM image of the CrN thin films. These films are dense and compact. According to the SEM measurements, the thickness of these films is approximately $0.76 \mu \mathrm{m}$. Fig. $2 \mathrm{c}$ shows the diffraction patterns of the $\mathrm{CrN}$ thin films deposited on the SUS440 samples. The peaks at $2 \theta=37.4^{\circ}$ and $43.6^{\circ}$ correspond to $\mathrm{CrN}$ phase (ICSD card \#11-0065). A CrN thin film is formed after deposition on the SUS440 substrate. The peaks at $2 \theta=44.6^{\circ}, 50.5^{\circ}$, and $64.6^{\circ}$ correspond to the SUS440 substrate. The diffraction peaks of $\mathrm{Cr}$ at $2 \theta=44.4^{\circ}$ and $64.6^{\circ}$ overlap with those of the substrate. This result is confirmed by the too high concentration (98.8 wt. \%) of $\mathrm{Cr}$ as depicted in Fig. 2d than that by stoichiometry in $\mathrm{CrN}$ phase ( 78.8 wt. \%). Besides that EDS would not detect the $\mathrm{Cr}$ in the substrate cause of other elements such as Fe with an even higher concentration in the substrate also could not be detected. Therefore, the $\mathrm{Cr}$ target is not completely transformed to $\mathrm{CrN}$ during the film formation. Hence, the film consists of $\mathrm{CrN}+\mathrm{Cr}$ phases.

Fig. 3 shows the effects of bias voltages on the surface hardness of the $\mathrm{CrN}$ thin films deposited on the SUS440 samples. The surface hardness of these films increases initially and then decreases as the bias voltage increases. The highest hardness of approximately $1492 \mathrm{HV}$ is observed at the bias voltage of $-20 \mathrm{~V}$. High negative bias voltages generally increase the energy of incident particles. Hence, a high value of surface hardness of the $\mathrm{CrN}$ films is archived in this study. As the bias voltage increases, the bombardment energy of the incident particles on the substrate increases also, thereby causing internal stress and increasing surface hardness. However, the hardness decreases rapidly when the bias voltage exceeds $-20 \mathrm{~V}$ probably due to the lattice relaxation and recrystallization of the superfluous bombarding energies [11] and/or defects, damage the film. 

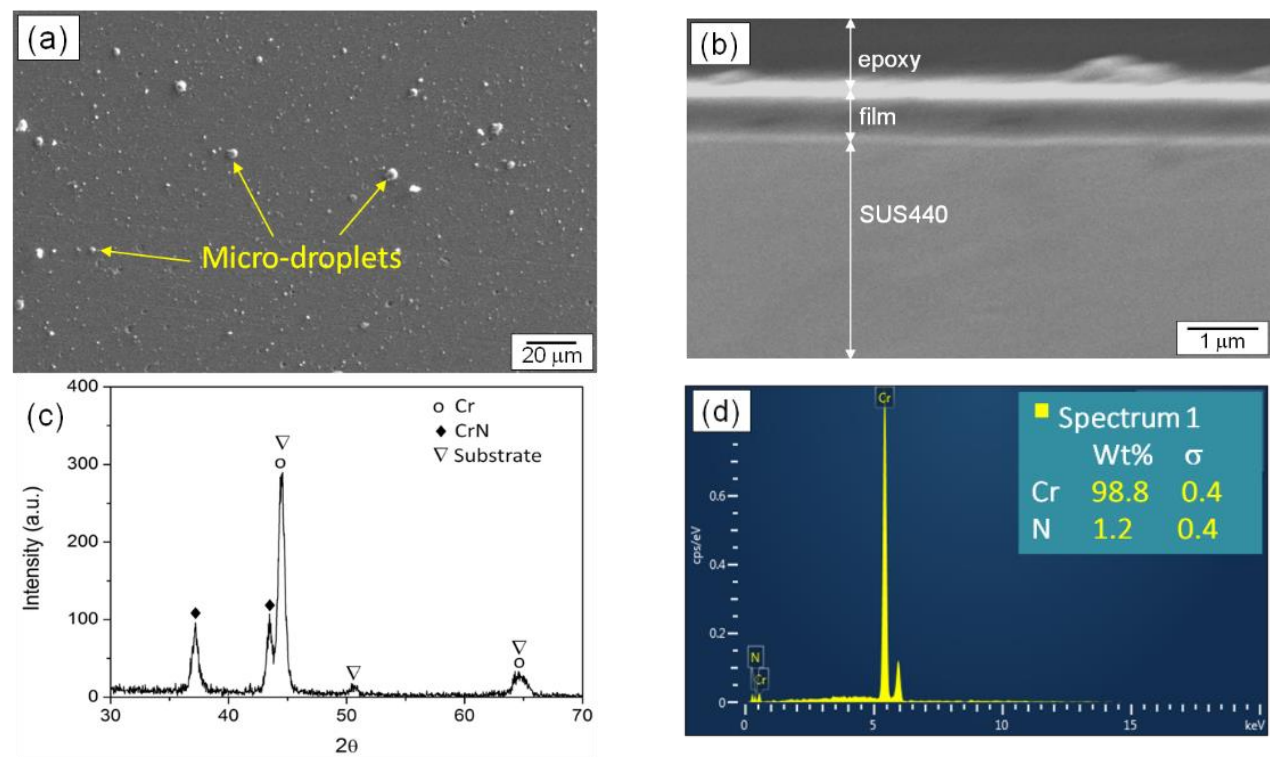

Fig. 2 CrN thin films deposited on the SUS440 samples at the bias of -20 V. (a) Top-view SEM image, (b) cross-sectional SEM image, (c) XRD pattern, and (d) EDS of the surface

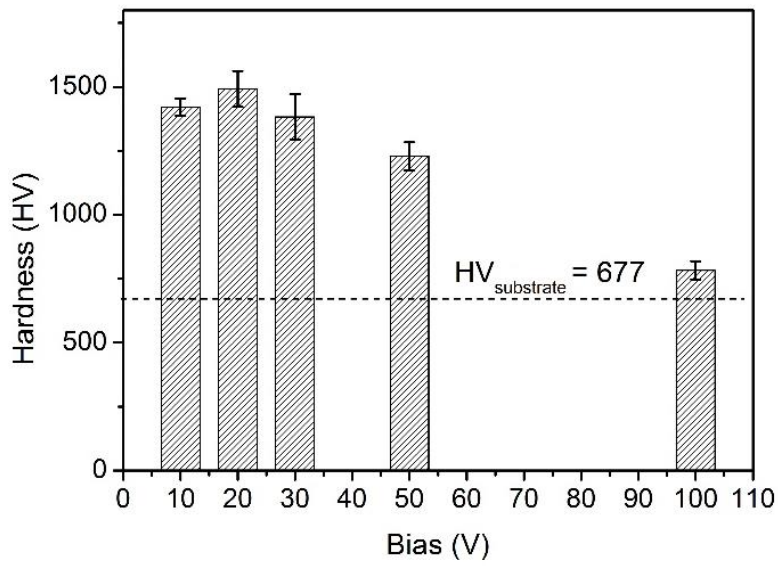

Fig. 3 Effects of the bias voltages on the surface hardness of the $\mathrm{CrN}$ thin films deposited on the SUS440 samples

Fig. 4 shows the optical images of the $\mathrm{CrN}$ thin films (as-deposited and after the Rockwell-C test) at different bias voltages. These films were deposited with many microdroplets. At the bias voltage of $-100 \mathrm{~V}$, the $\mathrm{CrN}$ film is delaminated (Fig. 4d). For all coated samples in this study, extended delamination at the vicinity of the imprint indicates poor interfacial adhesion (HF6). Further study, such as those with an increase in deposition time and new substrate materials, should be conducted to investigate the adhesion of the deposited $\mathrm{CrN}$ thin films. According to the results of the current study, at high bias voltages, delamination occurs severely, thereby further reducing the adhesion of the $\mathrm{CrN}$ thin films. This behavior can be attributed to an excessive intensity of residual stress, which can damage coatings and/or create adhesion failure [17]. 

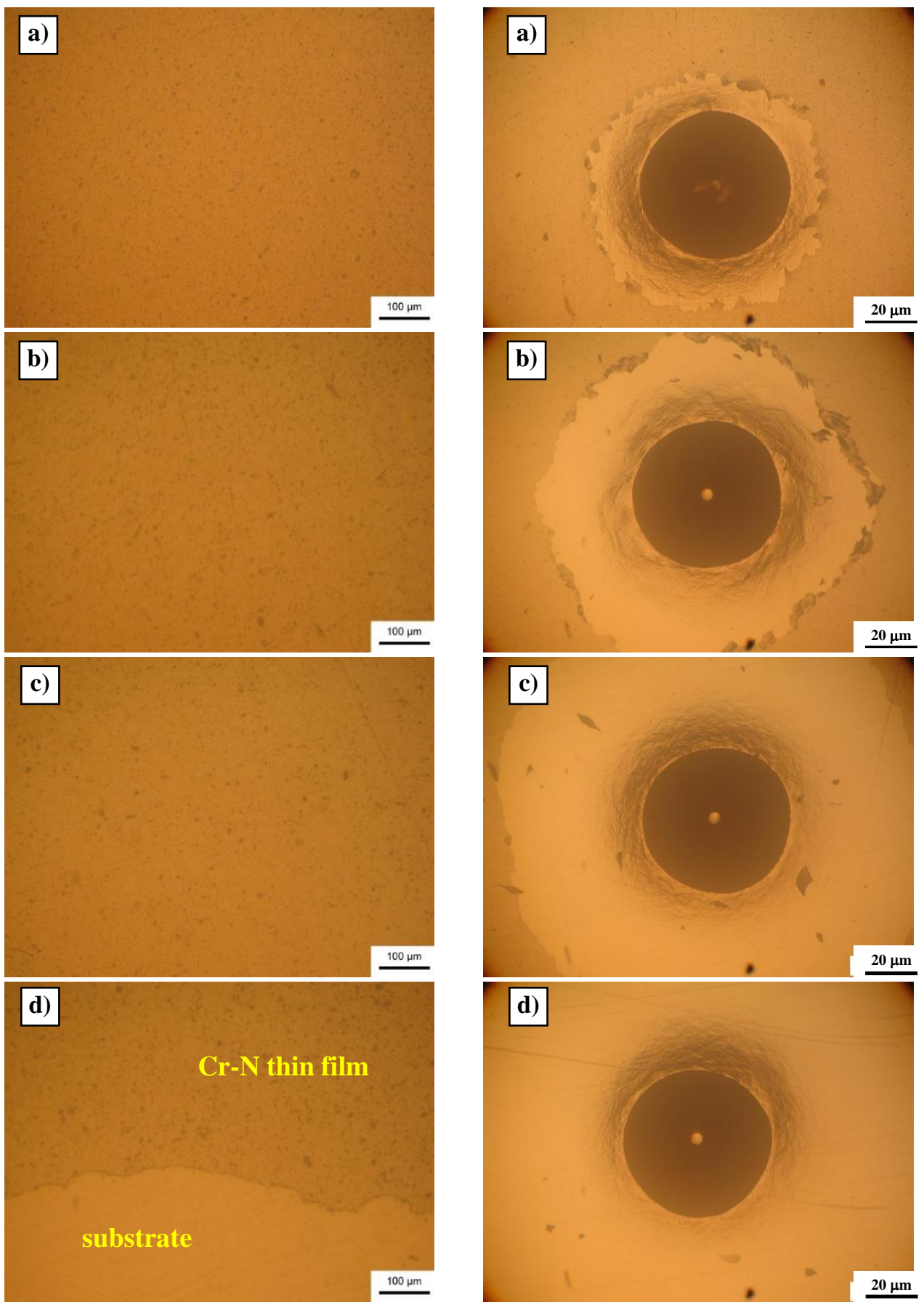

Fig. 4 Top-view optical images (before [left] and after the Rockwell-C indentations [right]) of the CrN thin films deposited on the SUS440 samples at the bias voltages of (a) $-20 \mathrm{~V}$, (b) $-30 \mathrm{~V},(\mathrm{c})-50 \mathrm{~V}$, and (d) $-100 \mathrm{~V}$ 


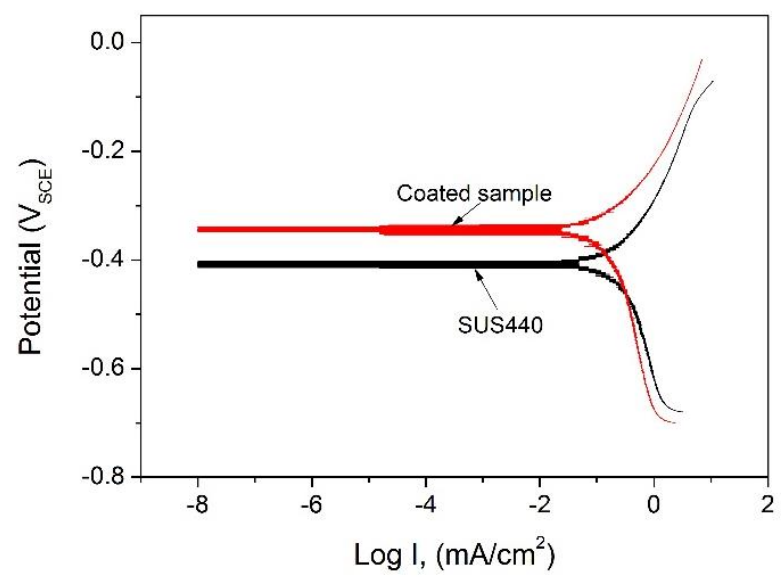

Fig. 5 Polarization curves of coated and uncoated samples in $3.5 \mathrm{wt} . \% \mathrm{NaCl}$ aqueous solution

Fig. 5 shows the anodic polarization curves in $3.5 \mathrm{wt} . \% \mathrm{NaCl}$ aqueous solution for the uncoated and $\mathrm{CrN}$-coated samples at the bias voltage of $-20 \mathrm{~V}$. The corrosion potential and corrosion current density are $-0.34 \mathrm{~V}$ and $0.119 \mathrm{~mA} / \mathrm{cm}^{2}$, respectively, for the coated sample and $-0.42 \mathrm{~V}$ and $0.316 \mathrm{~mA} / \mathrm{cm}^{2}$, respectively, for the uncoated sample. The coated sample has a more positive corrosion potential value than the uncoated sample. On this basis, the coating shifts the corrosion potential to higher positive $\mathrm{E}_{\text {corr. }}$ values. Therefore, a stable electrode potential is achieved, and the corrosion resistance of the coated sample is improved. $\mathrm{I}_{\text {corr. }}$ is commonly utilized as an index for evaluating corrosion resistance. In this study, the $\mathrm{I}_{\text {corr. }}$ is significantly reduced after $\mathrm{CrN}$ deposition. Thus, the corrosion resistance of the coated sample has an evident enhancement compared with that of the uncoated sample.

\section{Conclusions}

$\mathrm{CrN}$ thin films with a thickness of $0.76 \mu \mathrm{m}$ were deposited on SUS440 stainless steel samples by arc plasma evaporation. The hardness of these films increased initially and then decreased as the bias voltage increased. The highest hardness of approximately $1492 \mathrm{HV}$ was observed at the bias voltage of $-20 \mathrm{~V}$. These films consisted of $\mathrm{CrN}+\mathrm{Cr}$ phases with many microdroplets and poor interfacial adhesion. They were delaminated when deposited at the bias voltage of $-100 \mathrm{~V}$. Compared with the corrosion resistance of the uncoated sample, that of the coated sampled was enhanced.

\section{References}

[1] S. K. Tien, J. G. Duh: Thin Solid Films, Vol. 494, 2006, No. 1-2, p. 173-178, http://dx.doi.org/10.1016/j.tsf.2005.08.198

[2] P. H. Mayrhofer, G. Tischler, C. Mitterer: Surface \& Coatings Technology, Vol. 142-144, 2001, p. 78-84, http://dx.doi.org/10.1016/S0257-8972(01)01090-8

[3] C. He'au, R. Y. Fillit, F. Vaux, F. Pascaretti: Surface \& Coatings Technology, Vol. 120-121, 1999, p. 200-205, http://dx.doi.org/10.1016/S0042-207X(02)00146-X

[4] S. Y. Lee, B. S. Kim, S. D. Kim, G. S. Kim, Y. S. Hong: Thin Solid Films, Vol. 506-507, 2006, p. 192-196, http://dx.doi.org/10.1016/j.tsf.2005.08.027 
[5] Y. P. Purandare, A. P. Ehiasarian, Eh. P. Hovsepian: Journal of Vacuum Science \& Technology A, Vol. 26, 2008, No. 2, p. 288-296, http://dx.doi.org/10.1116/1.2839855

[6] T. Suzuki, H. Saito, M. Hirai, H. Suematsu, W. Jiang, K. Yatsui: Thin Solid Films, Vol. 407, 2002, No. 1-2, p. 118-121, http://dx.doi.org/10.1016/S0040-6090(02)00023-8

[7] M. Zhang, M. K. Li, K. H. Kim, F. Pan: Applied Surface Science, Vol. 255, 2009, No. 22, p. 9200-9205, http://dx.doi.org/10.1016/j.apsusc.2009.07.002

[8] M. Holzherr, M. Falz, T. Schmidt: Surface \& Coatings Technology, Vol. 203, 2008, No. 5-7, p. 505-509, http://dx.doi.org/10.1016/j.surfcoat.2008.05.054

[9] V. M. Vishnyakov et al.: Thin Solid Films, Vol. 497, 2006, No. 1-2, p. 189-195, http://dx.doi.org/10.1016/j.tsf.2005.05.005

[10] T. Bin, Z. Xiaodong, H. Naisai, H. Jiawen: Surface \& Coatings Technology, Vol. 131, 2000, No. 1-3, p. 391-394, http://dx.doi.org/10.1016/S0257-8972(00)00769-6

[11]X. S. Wan, S. S. Zhao, Y. Yang, J. Gong, C. Sun: Surface \& Coatings Technology, Vol. 204, 2010, No. 11, p. 1800-1810, http://dx.doi.org/10.1016/j.surfcoat.2009.11.021

[12]Z. K. Chang, X. S. Wan, Z. L. Pei, J. Gong, C. Sun: Surface \& Coatings Technology, Vol. 205, 2011, No. 19, p. 4690-4696, http://dx.doi.org/10.1016/j.surfcoat.2011.04.037

[13]D. Wang, T. Oki: Thin Solid Films, Vol. 185, 1990, No. 2, p. 219-230, http://dx.doi.org/10.1016/0040-6090(90)90086-S

[14] N. Vidakis, A. Antoniadis, N. Bilalis: Journal of Materials Processing Technology, Vol. 143144, 2003, p. 481-485, http://dx.doi.org/10.1016/S0924-0136(03)00300-5

[15]H. Ljungcrantz, L. Hultman, J. $\quad$ E. Sundgren, G. Hakansson, L. Karlsson: $\quad$ Surface \& Coatings Technology, Vol. 63, 1994, p. 123-128, http://dx.doi.org/10.1016/S02578972(05)80016-7

[16]C. Rebholz, H. Ziegele, A. Leyland, A. Matthews: Surface \& Coatings Technology, Vol. 115, 1999, No. 2-3, p. 222-229, http://dx.doi.org/10.1016/S0257-8972(99)00240-6

[17] R. O. E. Vijgen, J. H. Dautzenberg: Thin Solid Films, Vol. 270, 1995, No. 1-2, p. 264-269, http://dx.doi.org/10.1016/0040-6090(95)06984-4

\section{Acknowledgements}

This research is supported by the Hanoi University of Science and Technology (HUST), under project number T2018-PC-088. 